This item was submitted to Loughborough's Research Repository by the author.

Items in Figshare are protected by copyright, with all rights reserved, unless otherwise indicated.

\title{
Reducing work-related Musculoskeletal Disorders (MSDs) through design: views of ergonomics and design practitioners
}

PLEASE CITE THE PUBLISHED VERSION

http://dx.doi.org/10.3233/WOR-152126

\section{PUBLISHER}

IOS Press (@) The authors)

\section{VERSION}

AM (Accepted Manuscript)

\section{PUBLISHER STATEMENT}

This work is made available according to the conditions of the Creative Commons Attribution-NonCommercialNoDerivatives 4.0 International (CC BY-NC-ND 4.0) licence. Full details of this licence are available at: https://creativecommons.org/licenses/by-nc-nd/4.0/

\section{LICENCE}

CC BY-NC-ND 4.0

\section{REPOSITORY RECORD}

Punchihewa, Himan K.G., and Diane E. Gyi. 2019. "Reducing Work-related Musculoskeletal Disorders (msds) Through Design: Views of Ergonomics and Design Practitioners". figshare. https://hdl.handle.net/2134/19506. 


\title{
Reducing work-related Musculoskeletal Disorders (MSDs)
}

\section{through design: Views of ergonomics and design practitioners}

\begin{abstract}
BACKGROUND: Work-related Musculoskeletal Disorders (MSDs) affect the well-being of workers. Unfortunately, user requirements for design to reduce workplace risk factors for MSDs are not always effectively communicated to designers creating a mismatch between the user requirements and what is ultimately produced.

OBJECTIVE: To understand the views of practitioners of design and ergonomics regarding tools for participatory design and features they would like to see in such tools.

METHODS: An online questionnaire survey was conducted with a cohort of practitioners of ergonomics and design ( $\mathrm{n}=32$ ). In-depth interviews were then conducted with a subset of these practitioners $(n=8)$. To facilitate discussion, a prototype integrated design tool was developed and demonstrated to practitioners using a verbalized walkthrough approach.

RESULTS: According to the results of the questionnaire survey, the majority (70\%) believed an integrated approach to participatory design would help reduce work-related MSDs and suggested ways to achieve this, for example, through sharing design information. The interviews showed the majority $(\mathrm{n}=7)$ valued being provided with guidance on design activities and ways to manage and present information.

CONCLUSION: It is believed that an integrated approach to design in order to help reduce work-related MSDs is highly important and a provision to evaluate design solutions would be desirable for practitioners of design and ergonomics.
\end{abstract}

Keywords: design process; participatory design; design methods

\section{Introduction}

Work-related musculoskeletal disorders (MSDs) affect the health and well-being of workers and can hinder growth in the industrial sector causing staggering expense [1]. Attempts have been made to reduce MSDs in the working population, for example, intervention programs [2-5], standards [6] and guidelines [7,8] have been developed to try to eliminate workplace risk factors, but they are still commonplace. Research suggests that more intervention approaches are required and that methods currently being used to reduce the risk of MSDs among workers could be improved $[9,10]$. Adherence to ergonomics in design together with a full assessment of work systems would help curb work-related MSDs [1].

A drawback in the design process is the mismatch between user requirements to reduce workplace risk factors for MSDs and what is ultimately produced [11,12]. Stakeholders in the design process include users that directly interact with equipment and processes and practitioners such as engineers, designers and others such as ergonomists, occupational health professionals and health and safety personnel that may be involved in the design process and influence design decisions. However, the involvement of such professionals varies [13] and 
user focused design requirements to reduce workplace risk factors for MSDs are not always effectively and efficiently conveyed preventing appropriate solutions being incorporated in the next generation of designs. Thus, a mechanism to fill this void between the users and the practitioners of design may lead to a better understanding of the design requirements that could potentially reduce the risk of work-related MSDs. In this pursuit, understanding user requirements pertinent to reducing work-related MSDs is vital. Solutions can then be derived for the identified requirements for design, and suitable solutions selected and effectively presented to help detailed design.

Participatory design could play a major role in identifying requirements for design [14]. For instance, a review [15] reports that participatory ergonomics interventions show positive impacts, and focuses more on physical and work process changes. It also mentions that these interventions need the right practitioners to be involved, appropriate ergonomics training and clear responsibilities. Involvement of users/workers in such programs is considered paramount to help provide lasting solutions to the MSD related problems in industry $[16,17]$. Supporting this notion, a study of workers involved in different work tasks, i.e. cleaners, joiners and plumbers, to assess worker knowledge and ability to participate in the design process showed that they were able to identify requirements for design with respect to identifying workplace factors that give rise to higher MSD risk levels [18]. Various methods such as systematic brainstorming techniques and experience-based judgements could be used to determine solutions. These techniques can enhance knowledge of stakeholders in the design process to develop solutions to help reduce work-related MSDs. In order to collate and effectively communicate design information to the design teams, methods such as quality function deployment (QFD) [19] can be used. These methods help gather requirements for design, map solutions to these requirements and relate other necessary design information required by design practitioners such as technical details to the solutions. Such methods have successfully been implemented in various industrial sectors such as engineering and services industry [20]. Although limited, applications of these methods in ergonomics are reported in the literature. For instance, studies show the potential in helping to manage design information to reduce workplace risk factors for developing MSDs [21,22]. This is further accentuated by the findings of a review [15] where program support, organizational knowledge and communication are discussed as key facilitators and barriers for participatory ergonomics interventions.

In order to investigate the value of such an approach to the intended users as an effective and efficient way of reducing work-related MSDs, the potential and feasibility for different practitioners must be understood. Thus, a survey of practitioners of ergonomics and design was conducted to identify tools and techniques that were 
currently being used and to explore the importance of these within different stages of the design process, in reducing work-related MSDs. Secondly, in-depth interviews were conducted with a sub-sample of these practitioners to understand their views with regard to reducing work-related MSDs through design. In order to facilitate discussion, a prototype integrated design tool was demonstrated to them and their views with respect to the proposed elements of the design process were captured.

\section{Data collection}

\subsection{Questionnaire survey}

In order to understand methods currently used by practitioners of ergonomics and design involved in reducing work-related MSDs, the 57 registered consultancies (representing 144 ergonomists) listed in the database of the Institute of Ergonomics and Human Factors (IEHF), UK were contacted by email. It was acknowledged that for some consultancies, the research would not be relevant. In addition, a notice requesting participation in the study was published in the IEHF monthly newsletter, 'The Ergonomist', which has an estimated readership of 1400 (personal communication with the editor).

A questionnaire survey was developed, and was hosted using SurveyMonkey ${ }^{\mathrm{TM}}$. The content is detailed in Table 1. The link generated by the survey tool was attached to the email requests that were sent to the practitioners. The expected time to complete the questionnaire was 5-10 minutes. In the last section of the questionnaire, practitioners were asked to comment on the need for an integrated participatory design tool. Practitioners were then asked to rate the importance of the elements of the proposed tool on a 7-point scale (1= not important to 7= highly important). These elements are described in Section 2.2 and illustrated in Figure 1.

Table1. Summary of the questionnaire (within brackets, included categories)

\begin{tabular}{ll}
\hline Section & \multicolumn{1}{c}{ Elicited information } \\
\hline Introduction & Brief about the research and the objectives of the survey; researcher contact details. \\
Personal and job & Gender. \\
information & Current occupation (ergonomist, consultant, lecturer, health and safety practitioner, \\
& engineer, human factors engineer, designer manager, other). \\
& Job responsibilities (manage ergonomics projects, user needs analysis, equipment and \\
& task design, conducting user trials, MSD risk assessment, user measurement assessment,
\end{tabular}


other).

Experience (0-5, 6-10, 11-20, $\geq 21$ years).

Expertise as a practitioner (anthropometry/biomechanics, job/task analysis, evaluation of MSD risk, management of work-related MSDs, system analysis and design, evaluation of products/systems, product/system development, product system design and testing, user requirements analysis and specification, participatory ergonomics, other).

Participatory Methods used to:

methods to help assess MSD risk (rapid upper limb assessment- RULA [23], rapid entire body assessmentreduce workREBA [24], body discomfort scale [25]), quick exposure check- QEC [26], Ovako working related MSDs posture analysis system- OWAS [27], Posture, activity, tools and handling- PATH [28], other).

identify user requirements to reduce work-related MSDs (questionnaire, user-interviews, focus groups, observation techniques, checklists, experience-based judgements, other). prioritise user requirements.

develop specific design solutions (ergonomics guidelines, study similar cases, innovation, experience-based judgments, other).

help innovation and views on formal or informal participatory processes used.

Ratings for the performance of methods/tools currently used with regard to the elements of the proposed design tool such as identifying MSD risks and obtaining user requirements (using a scale $1=$ very poor to $7=$ excellent).

A participatory Importance of an integrated tool to help the process involved in designing/improving (using design tool to a scale $1=$ not important to $7=$ highly important).

help reduce $\quad$ Rating of importance of elements of the proposed design tool such (using a scale $1=$ not work-related important to $7=$ highly important).

MSDs Additional elements required.

Further research Interest in participation in an interview and try out a new prototype design tool. 


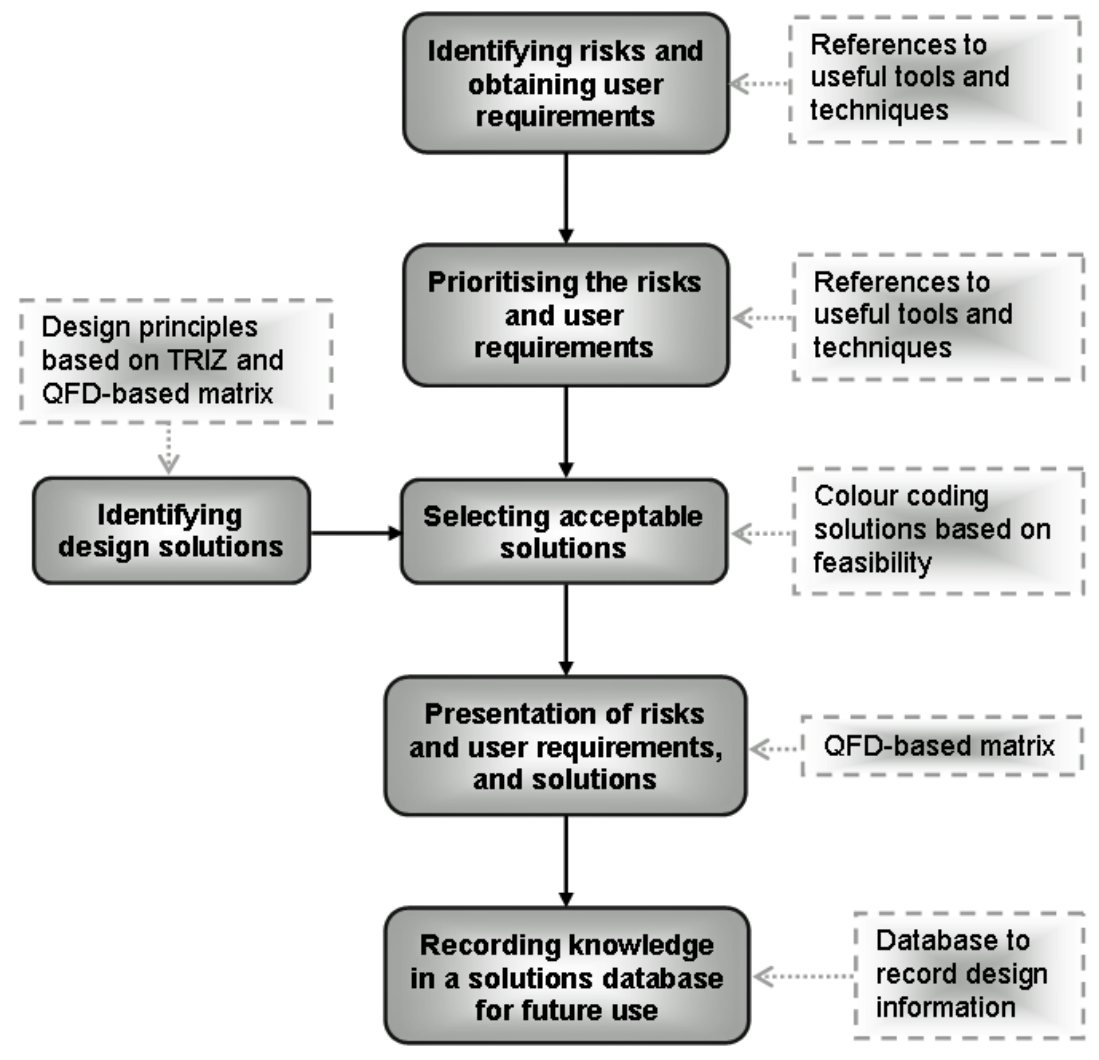

Figure 1. Proposed elements of the integrated design tool - Source: [29]

\subsection{Interview study}

19 respondents expressed an interest in taking part in an interview study, but three were excluded for practical reasons. Thus, 16 practitioners were contacted to conduct the interviews. The Loughborough University ethical guidelines for studies involving human participants [30] were observed at all times. Interviewees were informed about the purpose of the study, and the date and time for the interviews were arranged. The prototype tool is depicted in Figure 1.

The integrated design tool was developed using Microsoft ${ }^{\circledR}$ Office-based tools (e.g. Excel sheets) to facilitate activities in the design process. It was structured according to six elements of the design process which were identified from the literature (e.g. [13,31]). For the first two elements, a variety of commonly used techniques, such as questionnaires, interviews and Rapid Entire Body Assessment (REBA) can be used to identify and prioritize risks. With regard to identifying design solutions, the design principles used in the theory of inventive problem solving-TRIZ [32], for instance, segmentation, symmetry change and nesting were used to help systematically identify design solutions, which could help reduce workplace risk factors for developing MSDs. With regard to selecting from possible acceptable solutions, principles of axiomatic design were used 
[33]. To help record knowledge for future applications/use, database techniques facilitated by an approach based on a modified house of quality matrix of QFD was suggested to integrate, record and present design information in order to facilitate communication.

The tool was made available to the practitioners by email a week prior to the interview date to facilitate indepth discussion. At the beginning of the interviews, each of the six elements of the proposed tool was demonstrated to the practitioners using a verbalized walkthrough approach [34]. The interviews were assisted by a guide that included questions to assess: the positive aspects (capabilities/feasibility) and negative aspects (limitations); appeal in the field environment, and any changes or alterations/modifications needed. Probing questions were asked to clarify the answers as necessary. The interviews took 60-90 minutes and were audiorecorded to ensure uninterrupted flow of the discussion.

\section{Analysis}

Descriptive analyses were conducted separately for the questionnaire survey and interviews. Frequency distributions were determined for each of the measures included in the questionnaire and were graphically presented. The constant comparative method [35,36] was used to identify themes which were then prioritized according to their frequency of occurrence in the analysis of both the questionnaire (open-ended responses) and the narratives of the interviews. The themes were classified according to the features of the design tool (Figure 1) and then further categorized according to the capabilities/feasibility, limitations and future development.

\section{Results}

Initially, a descriptive analysis of the questionnaire survey and the interviews is presented. Specific findings with regard to the features of the design process are then presented followed by views on the proposed integrated design tool. The findings of the interview study are presented according to the features of the tool.

\subsection{Questionnaire survey}

\subsubsection{Participants}

Data from the questionnaire were collected from January - August 2009. In all, 32 practitioners responded to the survey with 23 completing the entire questionnaire. Twenty-one out of the 32 respondents were from the IEHF registered consultancies and represented $21 \%$ of the registered consultancies that were contacted. The respondents were 59\% males and $41 \%$ females. 
A high percentage of respondents (66\%) identified themselves as ergonomists and 33\% of them were consultants. Almost $60 \%$ of the practitioners that identified themselves as lecturers also reported other occupation categories. All of the health and safety practitioners also identified themselves as ergonomists. Respondents that distinguished themselves as human factors engineers (6\%) were different from the respondents that identified themselves as engineers (6\%). The respondents that specified their occupation as 'other' included two researchers, an osteopath and an occupational health technician. The respondents held a variety of job responsibilities with $81 \%$ and $69 \%$ reporting that they manage ergonomics projects or are involved in user needs analysis. The majority also identified equipment and task design (62\%); conducting user trials (62\%) and MSD risk assessment (59\%) as their job responsibilities. Additionally, user measurement assessment was recognized as a job responsibility by $41 \%$ of the practitioners. Other responsibilities indicated by $28 \%$ of the respondents included conducting research, heuristic evaluation of artifacts, teaching, simulation using human modeling, training, evaluation of artifacts, health surveillance, method study and customer engagement. Only $16 \%$ of the practitioners reported less than two job responsibilities. 22\% of the practitioners reported job responsibilities in all listed job areas. Respondents had considerable experience as practitioners with the majority (65\%) reporting more than 10 years of experience. The majority of the respondents reported expertise in relation to a wide range of areas pertinent to MSDs and design (Figure 2). Practitioners indicated expertise in multiple areas, often selecting three or more areas.

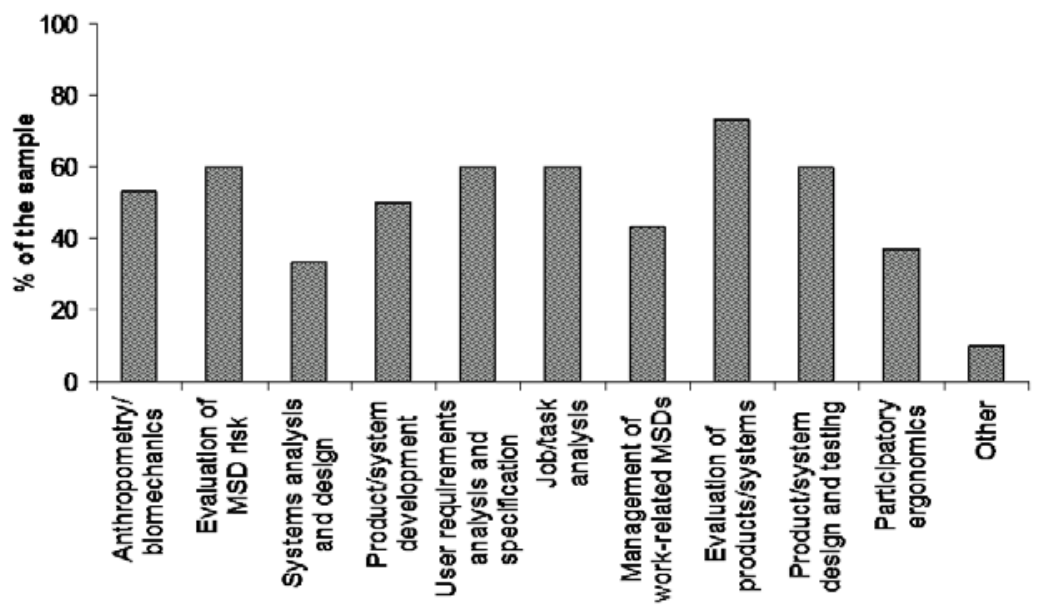

Figure 2. Areas of expertise of the respondents $(n=30)$

\subsubsection{Participatory methods currently used}

With regard to participatory methods currently used by them to help reduce work-related MSDs, 91\% not surprisingly used more than one. The majority of the respondents (75\%) completed the section on MSD risk assessment methods: RULA (79\%) and body discomfort scales (79\%) were the most commonly used methods. 
In addition, REBA (50\%), QEC (21\%) and OWAS (21\%) were also used by practitioners, but PATH was not used by any of these respondents. Other methods such as National Institute of Occupational Safety and Health (NIOSH) lifting equation, the Borg scale, electromyography (EMG) and expert evaluation were also mentioned. Two of the respondents indicated that they use proprietary methods for risk assessment, but did not reveal them. Out of the 23 respondents that completed the entire questionnaire, user-interviews (96\%), observation techniques (91\%), questionnaires (78\%) experience-based judgments (70\%) and checklists (65\%) were the most popular methods to identify user requirements. Focus groups were less popular (39\%) compared with the other methods. Data also indicated that the practitioners do not depend on a single method, but use a combination of methods to identify user requirements. Other methods included proprietary tools, QFD and task and job analysis, but no details were given. $39 \%$ of the respondents stated that they use formal methods/tools to help prioritize the user requirements for design in order to reduce work-related MSDs. Results from risk assessment, QFD, task and job analysis and proprietary tools were used by the respondents to prioritize the user requirements identified, however, details on these methods were not given.

Out of the 23 respondents, ergonomics guidelines (96\%), experience-based judgments (78\%) and studying similar cases (65\%) were used to identify solutions. 43\% used innovation helped by techniques such as identifying gaps in current practice, using ergonomics guidelines, experience-based judgments, looking at similar cases and brainstorming to develop design solutions. $87 \%$ of the respondents indicated that they relied on more than one method to develop design solutions. Other methods include the use of ergonomics standards, laboratory and field-based testing, human modeling, user consultations and evaluating the evidence base. Furthermore, 65\% of the practitioners responded positively to the question concerning the use of formal or informal participatory processes in design to reduce workplace risks for developing work-related MSDs. These were: involvement of users and other stakeholders in the different stages of the design process; iterative process to design and validate and failure mode and effects analysis (FMEA).

\subsubsection{Performance of methods/tools used}

The practitioners rated the performance of participatory methods/tools currently used by them on a 7-point scale (1= very poor to $7=$ excellent $)$ with regard to the elements of the proposed design tool and are graphically represented in Figure 3. 

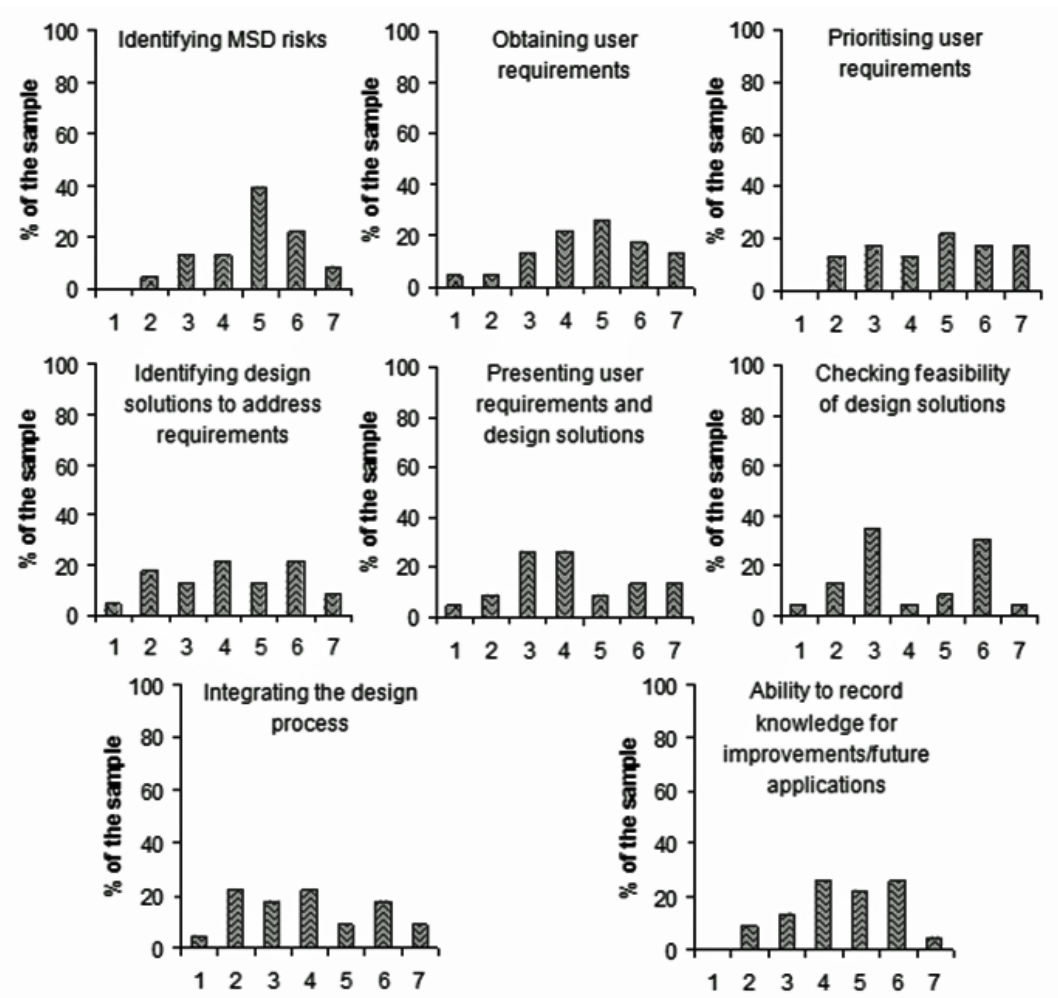

Figure 3. Ratings for performance of participatory methods/tools currently being used by the practitioners $(n=23)$

Practitioners were generally satisfied with the participatory methods currently being used to 'identify MSD risks' and 'record knowledge for improvements/future applications' with a mean rating of 5 (SD 1) and the majority rating the performance greater than 4 . The performance ratings of methods used for 'checking feasibility of design solutions' had a mean of 4 (SD 2), but the distribution showed two separate clusters of responses indicating that the practitioner opinion was divided. The ratings for the performance of the methods used for 'obtaining user requirements', 'prioritizing user requirements', 'identifying design solutions', 'presenting user requirements and design solutions' and 'integrating such elements' showed mixed responses. For methods for 'obtaining user requirements' and 'prioritizing user requirements', the mean ratings were 5 (SD 2) and the majority rated the performance greater than 4. For 'identifying design solutions', 'presenting user requirements and design solutions' and 'integrating the above elements' the mean ratings were 4 (SD 2) and the majority of the practitioners rated the performance less than 5 .

\subsubsection{Importance of an integrated tool}

A high importance (mean rating= 5: SD 1) was given to having an integrated tool to help the process involved in designing/improving and reducing work-related MSDs, and 69\% rated this aspect of the tool greater than 4 . Five respondents also identified possible benefits that an integrated design process could offer including avoiding 
sub-optimization, enabling management of risk estimation and problem solving tools, reducing project duration, and helping to cover broader aspects of work and validate solutions. Despite positive comments, three of the respondents were skeptical about an integrated approach and expressed reservations, and commented on possible drawbacks. For example, two practitioners reported that they already had ample experience to integrate information and had tools for integration.

\subsubsection{Importance of elements of the design process}

While Figure 3 presented the ratings for the performance of current methods/tools available to the practitioners to help reduce work-related MSDs, Figure 4 illustrates the perceived ratings on the importance of these elements as part of an integrated design tool given on a 7-point scale ( $1=$ not important to $7=$ highly important). $65-78 \%$ of the practitioners considered 'identifying MSD risks', 'obtaining user requirements', 'prioritizing user requirements', 'checking feasibility of design solutions', 'integrating the design process' and 'recording of knowledge for improvements/future applications' to be highly important for the design tool (mean rating= 6: SD 1). 'Identifying design solutions' and 'presenting user requirements and design solutions' comparatively perceived as less important (mean rating= 5: SD 1), although the majority ( $74 \%$ and $78 \%$ of the practitioners) rated the importance of these two elements greater than 4 .
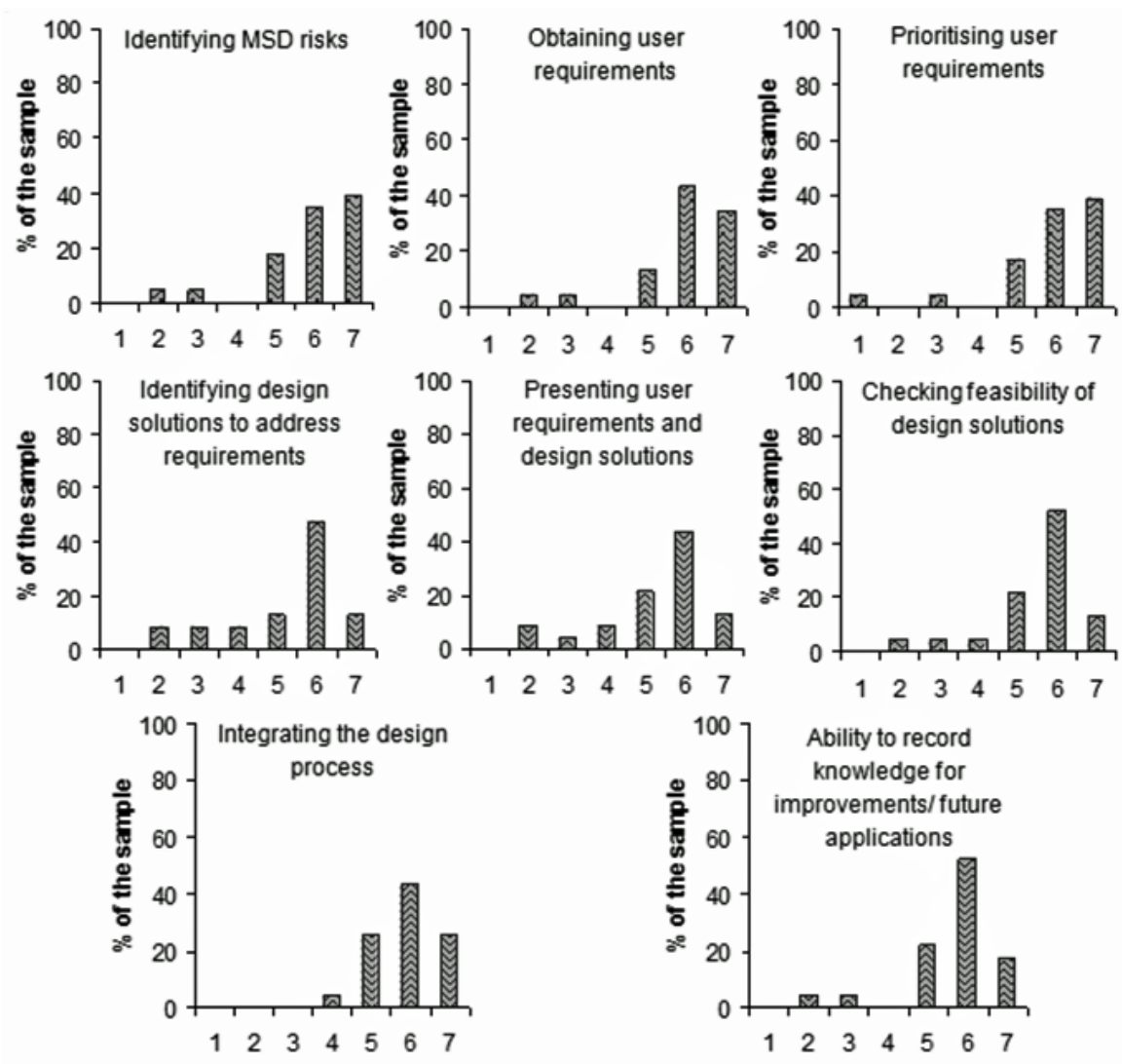

Figure 4. Ratings for importance of elements of the design process $(n=23)$ 
Eleven of the 23 practitioners commented on additional elements that would be useful for integrated design, which include the ability to record the rationale behind user requirements, to be able to prioritize and share design information among stakeholders and means of considering cost-benefits. In addition, it was reported that the process needs to ensure a systems approach and provide case studies and examples together with simple, quick and easy tools that demand little time and resources.

\subsection{Interview study}

\subsubsection{Participants}

Eight practitioners (five males and three females) took part in in-depth interviews. They expressed their roles as ergonomists $(n=5)$, consultants $(n=3)$, lecturers $(n=3)$ and engineers $(n=1)$ : three reported more than one category of occupation. All reported managing ergonomics projects as one of their job responsibilities. Other responsibilities were, conducting user trials $(n=7)$, user needs analysis $(n=6)$, equipment and task design $(n=5)$, user measurements assessment $(n=3)$ and MSD risk assessment $(n=2)$. The majority of practitioners $(n=5)$ reported over ten years of relevant experience. Areas of expertise reported were product/system development $(\mathrm{n}=$ 6), user requirement analysis and specification $(n=6)$, evaluation of products/systems $(n=6)$, product/system design and testing $(n=5)$, job/task analysis $(n=4)$, anthropometry/biomechanics $(n=3)$, participatory ergonomics $(n=3)$, evaluation of MSD risk ( $n=2)$ and systems analysis and design $(n=2)$.

\subsubsection{Practitioner views on the design process to reduce work-related MSDs}

Overall, views on integrating activities in the design process to reduce work-related MSDs through an integrated design tool were positive. Half of the practitioners supported the notion that integration of the design process helps enhance communication among the stakeholders of design, and emphasized that it is vital to facilitate communication of design requirements to practitioners of design such as engineers to reduce work-related MSDs. For instance, Participant 5 said:

“... you do need a tool and need more people involved so you can explore what they have got to offer in terms of their knowledge and expertise working in this sort of area... So if you've got any representatives of ergonomics, health and safety, engineers, designers, you got a multidisciplinary team then you cover a broader scope and also makes it easier to identify the relative feasibility. I can see that being very useful." 
In addition, four of the practitioners stated that it is important to guide practitioners through the design process. Some practitioners $(n=3)$ indicated the ability to omit or alternate between different phases in the design process based on practitioner prowess and the scale and scope of the undertaken project is also necessary. Furthermore, practitioners in general viewed that it is important to amalgamate the otherwise isolated methods, tools and techniques available to help work collectively towards reducing work-related MSDs. For example, Participant 3 mentioned:

"I am always interested in things, which, kind of, encapsulate. I can see the way in which you can logically take people, engineers being skeptics, through a process saying it is a cut through this [process] and these are the answers and if you got some more you want to add yourself and it's a way of recording that process."

The majority of the participants also mentioned limitations of the proposed integrated tool, but all suggested remedial action to address these. These further helped understand practitioner views regarding the design process to reduce work-related MSDs. All practitioners stated that clear guidance with regard to every aspect of the design process was required to help effectively integrate the design process. Half expressed that the entire process demonstrated in Figure 1 is long and would be time consuming. This emphasized the need for automated or semi-automated methods, tools and techniques: this was mentioned by six of the practitioners as a requirement for future development. The following comments by Participants 4 and 7 demonstrate this:

"My only concern is the amount of time it takes to go through the six steps. We have to go through the procedures and identify what we want to take out; what the issues are. Then, from issues we put it into something else and now is to say what the priority is and that list we put into the matrix and you need to go back and see what the solutions are and it's not always easy to find the time to do all of that. You will be asked a question one day and you are expected to find the solution the next day. It probably takes months after that to actually implement the solution, but they expect quick turn points.”

"The entire process is quite long and time consuming. Practitioners are aware of this. It is possible to perhaps have a modified version, which can be done quickly using automated aspects of the entire process.”

Another important aspect mentioned for future development was facilitating web-based online collaboration among the stakeholders of the design process. The following subheadings present the views of the practitioners 
regarding the design process to reduce work-related MSDs with respect to the six elements of the integrated design tool (Figure 1) used to facilitate discussion.

Identifying risks and obtaining user requirements

The majority of the practitioners $(n=5)$ identified that methods suggested in the integrated tool such as user interviews and REBA assessment for risk analysis were feasible to use and that it is especially important for inexperienced practitioners that methods are easily and readily used. For example, Participant 3 stated:

“...it's always nice when you have proposed methods. We have to actually get the thing and, you know, you have to go away and sort things out elsewhere and it's a nuisance. Probably, I would not bother to do that, whereas this, because it's there, it's really convenient you know! For practitioners, definitely being able to have a thing there is really useful. You see what it is and you can use it straight away."

Themes concerning 'capability/feasibility' also indicated that it is important to utilize the flexibility that methods offer to practitioners to help identify workplace risk factors for developing MSDs. The ability to triangulate data from different sources was also recognized as important. However, six practitioners stated that guidance is needed on selecting appropriate methods and how to use them. For instance Participant 6 stated:

“... I mean you've got the techniques there, you don't say whether you do one or both or whether you should definitely use REBA. If it's for experienced practitioners ergonomists, you probably don't need much. Otherwise, people with less experience, you might, without filling this page too much perhaps you can write a bit of general guidance and have that as another document that you can print off. I think it's more like when is a good time to do interviews. When is a good time to do observations, and a few hints and tips on doing them I think. Something you could follow up like references."

Another limitation in identifying risks and requirements, for two of the practitioners, was the difficulty in obtaining the co-operation of workers. Methods been used in the guidance material, which are not linked to subsequent elements of the proposed tool was observed as a limitation to integrate the design process by one of the practitioners. Guidance to help identify requirements for design from workers was also recognized as a need for future development viewed by two of the practitioners. Six practitioners viewed decision support techniques such as flowcharts as vital in providing succinct guidance to practitioners. In addition, the ability to access standards, guidelines and regulations, which are frequently being updated was viewed as important to enhance communication in the design process. Interestingly, the need to capture the reasons for particular design requirements was also considered important to facilitate communication by one of the practitioners. 


\section{Prioritizing the risks and user requirements}

All practitioners considered that in prioritizing risks and user requirements, the use of frequency analysis of themes was important and useful. This indicates the significance of providing simple procedures to help practitioners prioritize design requirements in a systematic and transparent manner. A comment made by Participant 7 is quoted:

"Being able to identify the frequency of comments and create themes from the users themselves, users will feel involved in the changes and the risks identified by the users that may have not been considered in-depth by the assessor. This may also have the biggest impact on improvement as they are identified by the workers."

Despite this, reliability of the prioritized list of requirements generated was cautioned by two of the practitioners. In particular, being limited to a set procedure, the possibility of missing important requirements was considered a major concern. The majority of the practitioners also thought that more training and guidance was needed in order for them to effectively and confidently prioritize requirements for design. For example, Participant 6 proposed:

"May be it's not a bad idea through each of the steps to have a one page sort of guide on how to do it, but not in detail, with something for a person who isn't sure to have a look at. Even if it's a very simple and practical like, now you are going to fill in this themes table and go through each interview record in turn.”

\section{Identifying design solutions}

Design parameters based on TRIZ were provided (e.g. divide or split into elements, reduce weight or balance weight) to help practitioners identify solutions to the requirements for design. All of the practitioners were of the view that using a set of design principles to help identify innovative solutions and a means of recording this information would be useful for industry. Seven out of eight practitioners indicated that collating design information in an easily presentable manner would be very useful in generating creative ideas. This would also enhance communication among stakeholders of the design process and thereby reduce work-related MSDs. For instance, Participants 2 and 6 respectively mentioned:

"Having design principles that facilitates you making proposals on how you like to change the design or whatever. ... It would make a huge difference in their ability, to be able to give something useful to the design engineer." 
"I like the design principles. I've not come across this before. There is a sort of distinction that people make between when you've got a problem, applying sort of low level fixes, or rethinking the whole problem going in to a higher level, perhaps thinking of a whole new approach, which could solve the problem in a completely new way.”

However, the need for guidance in identifying design solutions and how it needs to be presented for effective communication were viewed as important by seven of the practitioners.

\section{Selecting acceptable solutions}

Methods to easily visualize important design information were identified as useful for communication among different stakeholders of design. The color coding system proposed within the integrated design tool to classify design solutions according to their feasibility was appreciated by the majority of practitioners. Three of the practitioners also indicated that it is important to be able to check the relative feasibility of different solutions in the early stages of design. However, four of the practitioners also emphasized the importance of maintaining consistency within these methods. For example Participant 3 described:

"I agree, the traffic light system will always mean, red would mean something like it's too difficult or it's technically infeasible beyond the laws of physics or something like that. Amber would be ok there are possibilities, but there are potentially some significant problems need to be overcome. With time and effort you will be able to solve it. And green would be either it's easy to do or it absolutely solves the problem. That would be my simple interpretation."

Four practitioners also mentioned the need for guidance in order to help prioritize and select acceptable solutions from alternative solutions identified within the design process. Again, a flowchart-based approach was suggested by one of the practitioners to help provide guidance.

Presentation of risks and user requirements, and solutions

With regard to presentation of design information, all of the practitioners viewed that the ability to effectively present and visualize important design information is vital for communication in the design process. In particular, the ability to present all necessary design information in a single interface in the integrated tool was highly appreciated. In addition, the ability to take different stakeholders through the decisions made in the design process was viewed as important by five of the practitioners. For instance, Participant 3 and 4 respectively stated: 
"I think it's helpful when presenting solutions to engineers or anybody actually that you can take them through the story. So, rather than presenting them with the answers, that, you would take them through your previous one, because they can see where they come from and why you made the decisions you've made. People are always suspicious about being told this is the answer."

"Even if we came up with a requirement, the engineers will knock it back. Presenting it in a format that's compatible with their thinking is very good. And it takes so much trying to build that transition between the ergonomists and the engineers. We are very systematic in our thought process in our disciplines but there is a disparity."

Comparatively, there were only a few comments regarding limitations and directions for future development of the QFD matrix-based approach presented as part of the integrated tool. Although three of the participants commented that it was important to be able to separate the required design information from the rest when necessary. User requirements, design solutions, interactions between solutions, provision to present cost/benefit data, sketches and photographs were also identified as important for communication in identifying design solutions.

\section{Recording knowledge for future use}

The majority of the practitioners considered that it is useful to have access to a solutions database to store and retrieve important design information when necessary. However, half of the practitioners also thought that it would be additional work for them to update such database regularly emphasising the need to automate the data storage process. Participant 3 mentioned that:

“I probably wouldn't bother [keeping records], but I might come to a situation where actually I wish I had. You may be right. Are these linked automatically? Again as a practitioner and being lazy, I would probably, if I had to retype all this stuff, think I don't want to do that, I would be either looking to have automatically done for me."

Three of the practitioners also suggested using the internet to help them update the design information collaboratively and this would also help communicate with remote clients.

\section{Discussion}

The questionnaire survey was conducted to identify tools and techniques currently being used by practitioners and to explore the importance of these within the design process in reducing work-related MSDs. Then, using the 
proposed prototype design tool to facilitate discussion, the views of the practitioners regarding the design process were assessed through in-depth interviews.

Practitioners seemed comparatively satisfied with the participatory methods/tools currently being used for 'risk assessment' and 'recording knowledge for improvements/future applications'. Least satisfaction was reported for 'identifying design solutions', 'presenting user requirements and design solutions' and 'integrating the design process'. Ratings for participatory methods currently being used for 'checking feasibility of design solutions' showed a distinctive bi-modal distribution, which may be due to different technical backgrounds of practitioners. The literature also backs this view by concluding that ergonomics practitioners in general do not get involved later in the design process due to the deficiency in the competency with respect to technical ability, i.e. planning, delivery and evaluation [13]. This suggests the need for methods/tools to facilitate practitioners in carrying out these functions in the design process.

Adopting tools and techniques familiar to practitioners as much as possible would increase the ability to take on board the requirements of users in design. In the study [37], out of the 308 practitioners, 56\% used body discomfort scales, 52\% Rapid Upper Limb Assessment (RULA), 21\% the Ovako posture analyzing system (OWAS) and 18\% Rapid Entire Body Assessment (REBA). 79\%, 79\%, 21\% and 50\% respectively were the corresponding figures for these in the current survey. This variation is likely to be due to differences in the sample composition. Furthermore, $21 \%$ of the practitioners reported in the current study that they use the quick exposure check (QEC), a tool that had been tested by 150 practitioners for sensitivity, usability and inter/intra observer reliability [26,38]. However, the percentage of practitioners that use a specific tool may not reveal the accuracy or effectiveness of them [37]. These findings justify the need to use multiple tools and techniques followed by triangulation to assess MSD risks to help practitioners. In addition, observation techniques, user interviews, questionnaires and experience-based judgments were commonly used by practitioners to obtain user requirements although focus groups were less popular. This may be because several workers cannot be taken away from work at once owing to the current demands of industry. A literature review [39] also reveals that interview and questionnaire techniques (supported by observations) are frequently used in industry to obtain selfreports on workplace exposure. Many studies $[34,40,41]$ also indicate that these are popular methods. Thus, any method to help 'identify risks and obtain user requirements' in order to feed into the design process should be comparable with the methods widely being used in industry in order to have appeal for the practitioners.

The survey also indicated that the percentage of practitioners that use formal methods to help prioritize user requirements identified was low (39\%). The scoring systems used in risk assessment methods are largely 
hypothetical [39]. As a result, using such scores to prioritize user requirements as reported by some respondents may not be enough. Techniques to improve this process involve video recording of work and the use of computer software, but the time and expertise required can be financially demanding [39]. Although Quality Function Deployment (QFD) and proprietary tools were mentioned by the respondents as methods for prioritizing risks, the questionnaire was not able to capture details of how these were used.

The responses show that practitioners use information from different sources to help 'identify design solutions' to the problems identified in the workplace. Unfortunately, the questionnaire did not elicit details of specific methods used by them to help innovate. However, they appear to be broadly using techniques such as brainstorming, experience-based judgments and studying similar cases to suggest new solutions to reduce the risks of MSD through design. The literature also suggests using similar techniques to identify solutions to ergonomics related problems. For example, a brainstorming technique involving experts to help design new hand tools to reduce the risk of developing MSDs had been reported [42]. However, it is not clear what specific techniques the study used to induce ideas from the experts.

The survey further showed that presenting and checking the feasibility of design information is important and revealed additional elements that the practitioners deemed necessary to make the design activities/process more comprehensive. For example, the ability to record the rationale behind the user requirements and prioritise and share design information among stakeholders were deemed important. In a study consisting two questionnaire surveys that included 60 German QFD practitioners [43] reported similar requirements such as the possibility to easily visualize design information, represent information graphically and record information for knowledge reuse. However, detailed study of these aspects is necessary.

Respondents stressed that 'recording of knowledge for improvements/future applications' to be highly important and that automated data processing would be preferable. It has been reported in the literature that knowledge reuse is important for effective design and attempts have been made to provide solutions to the existing problems. As evidence, the literature reports that after studying the requirements in relation to data storage and retrieval, a prototype knowledge management system had been developed for decision support [44]. Functions of the system included, for example, functions for representing context with informal components and easy access to process knowledge. There have also been reports on instances where databases have been used when developing design methodologies. For instance, describes a software-based design system for concurrent engineering where environments for data and knowledge bases have been proposed in the literature [45]. 
However, specific information related to the integration of databases to manage design knowledge with respect to reduction of work-related MSDs was not found in the literature.

In the interview study, a prototype integrated design tool was used to facilitate more in-depth discussion with the practitioners on the design process and reducing work-related MSDs. To achieve this, all of the practitioners believed that it is vital to be able to present and visualize design information effectively. In addition, seven of the practitioners stated that the design principles used in the design tool such as 'divide or split up into elements' and 'reduce or balance weight' would be useful to communicate ideas. These were derived from the 40 TRIZ principles [32]. With reference to the literature on QFD, it has been developed as a tool to communicate design requirements from the users to the design teams to ensure design quality of both products and processes $[19,20,46]$. This could be helpful in realizing the needs of practitioners regarding the management of design information and enhancing communication.

Another aspect of the proposed integrated design tool was to elicit practitioner views on working through different stages of the design process. Most of the participants viewed that it is important to guide practitioners through the design process and accepted that a systematic and transparent way of prioritizing design requirements is beneficial. Adhering to participatory processes such as the 9-step process [13] and relating the design process to design models such as the Archer's prescriptive model [31] could help fulfill this need. Furthermore, design methods such as axiomatic design [33] and QFD [19] have been developed to facilitate practitioners in the design process, and these also can be utilized in this regard.

Interviews also provided further insights pertinent to practitioner needs in relation to the design process in general. For example, all of the practitioners indicated the importance of being able to prioritize the findings/themes identified/obtained from the users in a systematic manner providing some objectivity to softer data. All of the practitioners were also enthusiastic about being able to effectively manage and visualize design information in order to facilitate communication in the design process. Guiding practitioners through any procedures by providing structure to the design process is reported in the literature, for example it is revealed that, design methods help guide practitioners by providing structure and resources to complex design issues, and help deal with excessive amounts of information in the design process effectively [47]. These methods also make practitioners aware of the often overlooked aspects of design such as regulations, functional attributes, cultural differences and user centered design.

While appreciating the benefits of following an integrated design process that focused on enhancing communication and thereby reducing work-related MSDs, the majority of practitioners also had reservations. 
One of the foremost limitations identified was the time needed to follow the sequence of activities in the process as indicated by the integrated tool. Several comparable issues are identified with regard to collaborative product development [48], where it discusses that the alleged benefits of collaboration may not always be achieved in practice. Similar problems are also highlighted in the literature where it is reported that management difficulties increase exponentially with the increase in scale of design projects [49]. In relation to a study on assessing a design method, i.e. QFD, using nine industrial applications, concludes that the often-cited claim, 'shorter timeto-market' does not hold valid and has no scientific backing [50]. This emphasizes that naturally structured procedures would take time to deliver reliable results, and this may be the shortcoming envisaged by the practitioners in the current study. Consequently, it is important to pay attention to managerial and other factors such as resource allocation in the design process. In addition, the most frequently mentioned limitation was the inadequacy of guidance to enable the practitioners to follow a sequence of design procedures, and this may also be linked to the view regarding time to complete the process. The importance of providing assembly information in manufacturing is also discussed and an approach to present feature-based design models such as technological requirements and assembly hierarchies are detailed to understand the assembly processes of products [51]. Such experiences could be used to fulfill the needs of the practitioners regarding guidance and hence reduce the time requirement to follow the process.

\subsection{Limitations of the study}

Although there was a $17 \%$ response rate with respect to the registered consultancies, overall, the response rate was low for the online questionnaire, but the method is cost-effective compared to paper-based and mixed approaches [52]. However as a rule of thumb, a reasonable estimate for the response rate for online surveys is $11 \%$ [53]. In addition, the newsletter notice in the current study was a general invitation for participation and this can be another reason for the low response rate and as such the sample may not be representative of practitioners in the UK.

Out of the total of 32 respondents, 23 completed the entire questionnaire resulting in a completion rate of $72 \%$. Some of the practitioners mentioned that they are not involved in the entire design process to reduce workrelated MSDs and hence completed only the relevant sections of the questionnaire. Although guidelines were followed, another reason for this may be the effect of the online questionnaire layout design and the number of questions per screen [54]. 
The occupations, experience and expertise of the practitioners were in general comparable to the results of a previous survey of tools and methods used by 308 certified professional ergonomists [37] and a study of 107 ergonomics related practitioners and academics [55] from different parts of the world. It is also reported that job/task analysis and design (53\%), health and safety (42\%) and anthropometry/biomechanics (34\%) were the most common areas of expertise [37]. In the current study, the percentage of practitioners that considered job/task analysis as an area of expertise was $60 \%$ and that for anthropometry/biomechanics was $53 \%$.

The questionnaire study adopted a survey technique and provided only an elementary review of the design process. This is an inherent limitation of questionnaire survey techniques [56]. For this reason, extensive study is quintessential to evaluate the process in-depth. Expert evaluations where the processes or systems are evaluated by experts to identify capabilities and limitations are suitable for such analyses [57]. Thus, the interview study that was conducted using a prototype tool and a walkthrough approach to evaluate in-depth practitioner views is justified.

However, the results of the interview study may also have been affected by inherent limitations in conducting interviews such as the respondent's skill at self-observation [58]. Another limitation of the interview approach is when data saturation is assumed, but without any explanation of what it means and how it occurred [59]. Thus, recognizing the saturation point presents a challenge to qualitative research. In the current study however, no new themes emerged when the number of interviews reached eight suggesting data saturation and indicates that the sample size was probably adequate. Interestingly, a study provides insight into the number of participants required to evaluate a web-site from a study that involved a rigorous usability testing methodology [60]. It shows that six to nine participants were needed to evaluate, despite the general agreement in the literature that suggests four to six as appropriate.

Furthermore, walkthroughs followed by in-depth interviews with the practitioners helped to identify needs of the practitioners regarding the design process, but this approach can only provide limited information and may be biased $[57,58]$. For instance, it is reported that interviews may not yield all relevant issues due to the fact that interviewees are not always qualified to judge every aspect of a product or a process [57]. Although interviewing eight experienced practitioners reduced such shortcomings, further scrutiny of the process may be necessary.

With regard to the participant group for the interview study, all of the practitioners considered managing ergonomics projects as one of their job responsibilities. Therefore, they can be considered as active in industry. This reduces the bias that can occur due to a high proportion of one participant group with low experience in the industry. It is reported that overall, both practitioners and academics demonstrate confidence in the competencies 
expected from an ergonomics professional [61] as listed in the international ergonomics association (IEA) website. In addition, in a survey of professional ergonomists, 8.8\% categorized themselves as educators indicating that educators also take part in industrial projects as practitioners [37]. These studies minimize concerns about the relatively high proportion of academics (38\%) in the sample.

\section{Conclusion}

Ratings for the performance of participatory methods currently used by these practitioners were in general varied. Methods for identifying MSD risks, obtaining user requirements, prioritizing user requirements, checking feasibility of design solutions, integrating the design process and recording of knowledge for improvements/ future applications were all rated as highly important in any integrated design tool. In addition, the majority of practitioners also believed that an integrated approach to design in order to help reduce work-related MSDs was highly important. Other elements such as evaluating design solutions in terms of the cost-benefits of such solutions would be desirable.

The majority of practitioners that took part in the interview study viewed that methods are particularly needed to help prioritize requirements, identify solutions, present and manage design information and record knowledge for future use to help reduce work-related MSDs. The majority also considered that easy to follow guidance and automated procedures were a priority in any integrated tool. Half of these practitioners viewed that methods to help them communicate with other stakeholders in the design process and guide them through it were important.

\section{References}

[1] Buckle P. Ergonomics and musculoskeletal disorders: Overview. Occup. Med. 2005; 55(3):164-167.

[2] Haines H, Wilson JR, Vink P, Koningsveld E. Validating a framework for participatory ergonomics (the PEF). Ergonomics. 2002; 45(4):309-327.

[3] Kogi K. Facilitating participatory steps for planning and implementing low-cost improvements in small workplaces. Appl Ergonomics. 2008; 39(4):475-481.

[4] Zink KJ, Steimle U, Schröder D. Comprehensive change management concepts: Development of a participatory approach. Appl Ergonomics. 2008; 39(4):527-538. 
[5] Caroly S, Landry A, Cholez C, Davazies P, Bellemare M, Poussin N. Innovation in the occupational health physician profession requires the development of a work collective to improve the efficiency of MSD prevention. Work. 2012; 41(1):5-13.

[6] Karwowski W. Handbook of standards and guidelines in ergonomics and human factors. New Jersey: Lawrence Erlbausm Associates Inc.; 2006.

[7] NIOSH. Ergonomic guidelines for manual material handling. California: California Department of Industrial Relations (Cal/OSHA); 2007.

[8] OHSCO. MSD prevention toolbox: Getting started- Musculoskeletal disorders prevention series- Part 3A. Canada: Occupational Health and Safety Council of Ontario (OHSCO); 2008.

[9] Vink P, Lourusen E, Wortel E, Dul J. Rapid communication experiences in participatory ergonomics: Results of a roundtable session during the $11^{\text {th }}$ IEA congress, Paris. July 1991. Ergonomics. 1992; 35(2):123-127.

[10] Kogi K. Participatory methods effective for ergonomic workplace improvement. Appl Ergonomics. 2006; 37(4):547-554.

[11] Shinnar A, Indelicato J, Altimari M, Shinnar S. Survey of ergonomic features of supermarket cash registers: Short communication. Int J Ind Ergonomics. 2004; 34(6):535-541.

[12] Broberg O. Integrating ergonomics into engineering: Empirical evidence and implications for the ergonomists. Human Factors and Ergonomics in Manufacturing. 2007; 17(4):353-366.

[13] Vink P, Imada AS, Zink, KJ. Defining stakeholder involvement in participatory design processes. Appl Ergonomics. 2008; 39(4):519-526.

[14] Broberg O, Edwards K. User-driven innovation of an outpatient department. Work. 2012; 41:101-106.

[15] van Eerd D, Cole D, Irvin E, Mahood Q, Keown K, Theberge N, et al. Process and implementation of participatory ergonomic interventions: a systematic review. Ergonomics. 2010; 53(10):1153-1166.

[16] Wilson JR. Ergonomics and participation. In: Wilson JR and Corlett EN, editors. Evaluation of human work: A practical ergonomics methodology. $2^{\text {nd }}$ ed. London: Taylor and Francis; 1995. p. 1071-1096.

[17] Hignett S, Wilson JR and Morris W. Finding ergonomic solutions- participatory approaches: In-depth review. Occu Med. 2005; 55(3):200-207.

[18] Punchihewa HKG, Gyi DE. Development of a QFD based collaborative design approach to reduce workrelated musculoskeletal disorders (MSDs). Design Principles and Practices: An Int J. 2009; 3(6):207-223.

[19] Akao Y. Quality function deployment: integrating customer requirements into product design. Massachusetts: Productivity Press; 1990. 
[20] Chan L-K, Wu, M-L. Quality function deployment: A literature review. Euro J Operational Research. 2002; 143(3):463-497.

[21] Marsot J. QFD: A methodological tool for integration of ergonomics at the design stage. Appl Ergonomics. 2005; 36(2):185-192.

[22] Karwowski W. Ergonomics and human factors: The paradigms for science, engineering, design, technology and management of human-compatible systems- Invited plenary paper. Ergonomics. 2005; 48(5):436-463.

[23] McAtamney L, Corlett EN. RULA: A survey method for the investigation of work-related upper limb disorders. Appl Ergonomics. 1993; 24(2):91-99.

[24] Hignett S, McAtamney L. Rapid entire body assessment (REBA): Technical note. Appl Ergonomics. 2000; 31(2):201-205.

[25] Corlett EN. The evaluation of industrial seating. In: Wilson JR, Corlett EN editors. Evaluation of human work: A practical ergonomics methodology. London: Taylor \& Francis; 1990. p. 500-515.

[26] Li G, Buckle P. Evaluating change in exposure to risk for musculoskeletal disorders- A practical tool. UK: Health and Safety Executive; 1999.

[27] Karhu O, Kansi P, Kuorinka I. Correcting working postures in industry: A practical method for analysis. Appl Ergonomics. 1977; 8(4):199-201.

[28] Buchholz B, Paquet V, Punnett L, Lee D, Moir S. PATH: A work sampling-based approach to ergonomic job analysis for construction and other non-repetitive work. Appl Ergonomics. 1996; 27(3):177-187.

[29] Punchihewa HKG. The potential of quality function deployment (QFD) in reducing work-related musculoskeletal disorders. Loughborough University, UK: 2010.

[30] Loughborough University. Code of practice on investigations involving human participants: Revised and approved by Council. [Internet]. Leicestershire, Loughborough University. 2003. Available from: http://www.lboro.ac.uk/a dmin/committees/ethical/cophp/htm

[31] Cross N. Engineering design methods: Strategies for product design. $2^{\text {nd }}$ ed. West Sussex: John Wiley \& Sons; 1994.

[32] Rantanen K, Domb E. Simplified TRIZ: New problem solving applications for engineers and manufacturing professionals. Florida: CRC Press; 2002.

[33] Suh NP. The principles of design. New York: Oxford University Press Inc.; 1990.

[34] Stanton NA, Salmon PM, Walker GH, Barber C, Jenkins DP. Human factors methods: A practical guide for engineering and design. Hampshire: Ashgate Publishing Limited; 2005. 
[35] Glaser BG. The constant comparative method of qualitative analysis. Social Problems. 1965; 12(4):436445.

[36] Erlandson DA, Harris EL, Skipper BL, Allen SD. Doing naturalistic Inquiry: A guide to methods. California: Sage Publications, Inc.; 1993.

[37] Dempsey PG, McGorry RW, Maynard WAS. A survey of tools and methods used by certified professional ergonomists. Appl Ergonomics. 2005; 36(4):489-503.

[38] Li G, Buckle P. Current techniques for assessing physical exposure to work-related musculoskeletal risks, with emphasis on posture-based methods. Ergonomics. 1999; 42(5):674-695.

[39] David GC. Ergonomic methods for assessing exposure to risk factors for work-related musculoskeletal disorders: In-depth review. Occu Med. 2005; 55(3):190-199.

[40] Wilson JR, Corlett NE. Evaluation of human work: A practical ergonomics methodology. London: Taylor \& Francis; 1990

[41] Maguire MC. RESPECT: User-centred requirements handbook. Version 3.3. RESPECT Consortium. 1998. Available from: http://www.npl.co.uk/respect

[42] Kuijt-Evers LFM, Morel KPN, Eikelenberg NLW, Vink P. Application of the QFD as a design approach to ensure comfort in using hand tools: Can the design team complete the house of quality appropriately? Appl Ergonomics. 2009; 40(3):519-526.

[43] Herzwurm G, Mellis W, Schockert S, Weinberger C. Customer oriented evaluation of QFD software tools. Proceedings of the 3rd International Symposium on Quality Function Deployment. October 2-3. Linköping, Sweden. 1997; 1:309-323.

[44] Ramesh B, Tiwana A. Supporting collaborative process knowledge management in new product development teams. Decision Support Systems. 1999; 27(1-2):213-235.

[45] Sivaloganathan S, Evbuomwan NFO, Jebb A, Wynn HP. Design function deployment- a design system for the future. Design Studies. 1995; 16(4):447-470.

[46] Reich Y. Improving the rationale capture capability of QFD. Eng with Comp. 2000; 16(3-4):236-252.

[47] Green LN, Bonollo E. The importance of design methods to student industrial designers. Global J Eng Edu. 2004; 8(2):175-182.

[48] Bruce M, Leverick F, Littler D. Complexities of collaborative product development. Technovation. 1995; 15(9):535-552. 
[49] Franceschini F, Rossetto S. Quality function deployment: How to improve its use. Total Quality Management. 1998; 9(6):491-500.

[50] Lager T. The industrial usability of quality function deployment: A literature review and synthesis on a meta-level. R\&D Management. 2005; 35(4):409-426.

[51] Pham DT, Dimov SS. A system for automatic extraction of feature-based assembly information. Proceedings of Institution of Mechanical Engineers. 1999; 213(B):97-101.

[52] Greenlaw C, Brown-Welty S. A comparison of web-based and paper-based survey methods: Testing assumptions of survey mode and response cost. Evaluation Review. 2009; 33(5):464-480.

[53] Saunders M, Lewis P, Thornhill A. Research methods for business students. $4^{\text {th }}$ ed. Essex: Prentice Hall: 2007.

[54] Toepoel V, Das M, van Soest A. Design of web questionnaires: The effects of the number of items per screen. Field Methods. 2009; 21(2):200-213.

[55] Williams CA, Haslam RA. Core competencies in ergonomics- do we have them? In: Pikaar, R.N., Koningsveld EAP, Settels PJM editors. Proceedings of IEA 2006 Congress. Oxford: Elsevier Science Ltd.: 2006.

[56] Charlton SG. Questionnaire techniques for test and evaluation. In: Charlton SG, O’Brien TG editors. Handbook of human factors testing and evaluation. $2^{\text {nd }}$ ed. New Jersey: Lawrence Erlbaum Associates Publishers; 2002. p. 225-246.

[57] Rosenbaum S. Usability evaluations versus usability testing: When and why?. IEEE Trans on Prof Comm. 1989; 32(4):210-216.

[58] Armstrong SD, Brewer WC, Steinberg RK. Usability testing. In: Charlton SG, O’Brien TG editors. Handbook of human factors testing and evaluation. $2^{\text {nd }}$ ed. New Jersey: Lawrence Erlbaum Associates Inc.; 2002. p. 403-432.

[59] Bowen GA. Naturalistic inquiry and the saturation concept: A research note. Qual Research. 2008; 8(1):137-152.

[60] Dowding T, Johnson R. How many users does it really take?: Revisiting usability testing. Design Principles and Practices: An Int J. 2008; 2(2):65-72.

[61] Williams CA, Haslam RA. Exploring the knowledge, skills, abilities and other factors of ergonomics advisors. Theor Iss in Ergonomics Science. 2011; 12(2):129-148. 